\title{
Giant paratesticular liposarcoma: A case report and review of the literature
}

\author{
ZUWEI LI ${ }^{1,2^{*}}$, LIANG ZHOU ${ }^{1,3^{*}}$, LIWEN ZHAO ${ }^{1}$, PEIJIE CHEN ${ }^{1,2}$, YIFENG LIU ${ }^{1}$, \\ YU DING ${ }^{1}$, SHUOLEI SUN ${ }^{1}$, SHANGQI YANG ${ }^{1}$ and YONGQING LAI ${ }^{1}$ \\ ${ }^{1}$ Department of Urology, Peking University Shenzhen Hospital, Shenzhen 518036; \\ ${ }^{2}$ Shantou University Medical College, Shantou, Guangdong 515041; ${ }^{3}$ Department of Urology, \\ Guangzhou Medical University, Guangzhou, Guangdong 510006, P.R. China
}

Received November 20, 2017; Accepted December 28, 2017

DOI: $10.3892 / \mathrm{mco} .2018 .1577$

\begin{abstract}
Paratesticular liposarcoma is an infrequent tumor characterized by a growing, painless, inguinal or scrotal mass. Only about 200 cases have been reported as of yet in literature, however there are a few cases regarding giant paratesticular liposarcoma measuring over $10 \mathrm{~cm}$. The disease may be commonly misdiagnosed prior to operation. Improper treatment tends to lead to local recurrence and distant metastasis. The current report presents a case of a 51-year-old patient with a large, painless right scrotum. Magnetic resonance imaging revealed a 7.8x5.8x10.4 cm nonhomogeneous space-occupying lesion of the right testis, which was firstly diagnosed as a spermatocytoma. Following this, a radical orchiectomy of the right testis was performed, however, it appeared to be a dedifferentiated liposarcoma, following histopathological examination and immunohistochemistry. Due to the large size of the tumor, it is significant to report the characteristics, diagnosis and treatment of the similar cases. The current study additionally presents a supplementary review of previously published cases in literature and focuses on discussion regarding the clinical characteristics, diagnosis, histopathology and immunohistochemical features and treatment of this disease.
\end{abstract}

\section{Introduction}

Liposarcoma, a malignant tumor derives from mesodermal tissues, represents $\sim 20 \%$ of all sarcomas. Paratesticular liposarcoma (PLS) is a rare condition. To the best of our knowledge, about 200 cases of PLS have been reported to

Correspondence to: Professor Yongqing Lai, Department of Urology, Peking University Shenzhen Hospital, 1120 Lianhua Road, Shenzhen 518036, P.R. China

E-mail: yqlord@163.com

*Contributed equally

Key words: giant, paratesticular liposarcoma, literature review, tumor, sarcoma date (1). Giant PLS is more rare with only a few cases having been reported (2-6). Due to the rarity of the disease, there is no standardized guideline as regards its incidence, diagnosis, recurrence and treatment $(7,8)$. In this study, we present a case of a giant dedifferentiated PLS of the right testis with magnetic

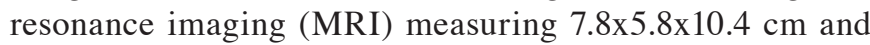
focus on the discussion about the clinical characteristics, diagnosis and treatment of this disease. Due to the giant size of this PLS, we report this case for the characteristics, diagnosis and treatment of the similar cases. The study was supported by the Ethics Committee of Peking University Shenzhen Hospital (Shenzhen, China) and written informed consent was obtained from the patient for the publication of the case details.

\section{Case report}

In July 2017, a 51-year-old man, with a complaint of swelling of the right scrotum for 2 months, was admitted to the Department of Urology of our hospital. He presented with a painless and slow-growing fixed mass in the right scrotum without conspicuous promoting or alleviating factors. There are no other signs or symptoms. A rigid mass in the right scrotum, about $8 \mathrm{~cm}$ in maximum diameter, was the only positive finding of physical examinations. There are no specific abnormalities in the laboratory and imaging examinations (hemogram, urinalysis, stool routine, ESR, $\beta$-human chorionic gonadotropin, a-fetoprotein, mycobacterium tuberculosis antibody Ig-G, liver and kidney function tests and chest X-ray). However, magnetic resonance imaging (MRI) demonstrated a 7.8x5.8x10.4 cmnonhomogeneous space-occupying lesion of the right testis (Fig. 1), which was considered as spermatocytoma at first.

Following the doctors' recommendation, the patient underwent a radical resection of the tumor combined with a right orchiectomy. An enlarged rigid testicle measuring 13x8x6 cm was removed out of the right scrotum. There is no evident inflammatory adhesion to the surrounding organs. On gross pathological examination, the resected specimen was an enlarged mass with a cut surface having yellowish lipoma-like texture. Final histopathological examination confirmed that it was a giant dedifferentiated liposarcoma (Fig. 2). Immunohistochemical analysis showed that CD34(-); SMA(+); S-100(-)(most of cells); ALK(-) and supported this diagnosis. 


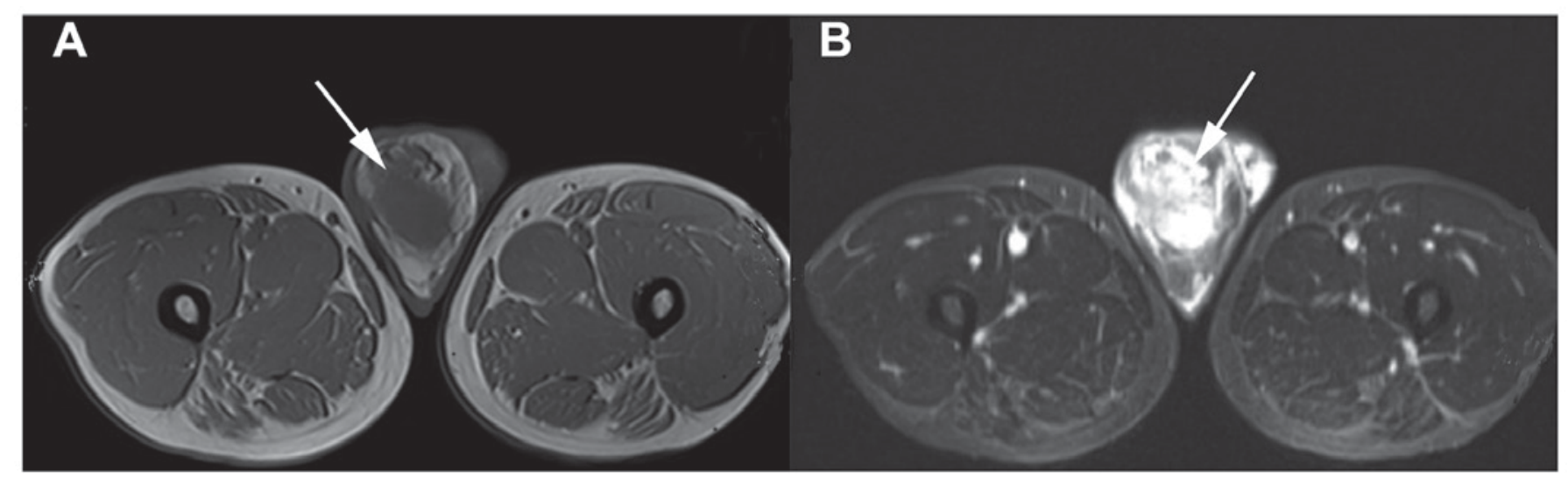

Figure 1. (A) Abdominal and (B) pelvic MRI scan showing a non-heterogeneous ill-defined mass, arrows.

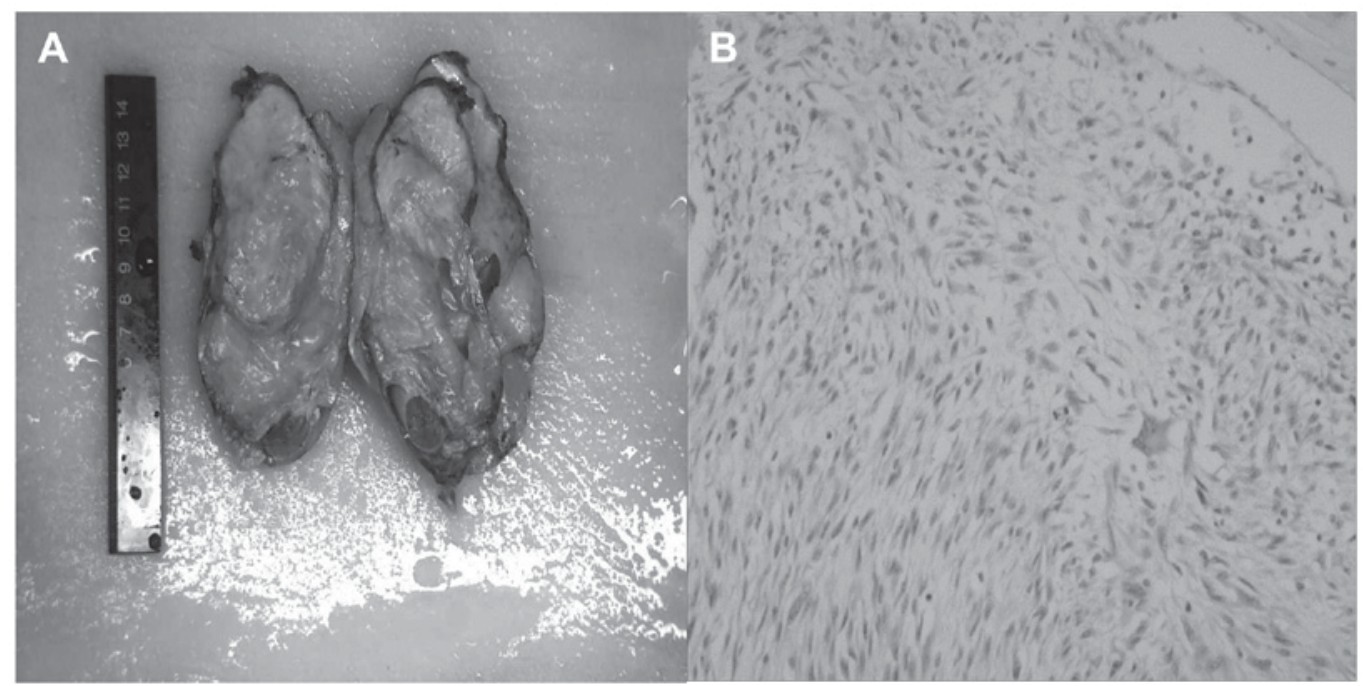

Figure 2. Macroscopic tumor characteristics. A cut surface having yellowish lipoma-like texture. The tumor was well-defined. (A) The right testis was not infiltrated. (B) Proliferating spindle cells containing mitotic activity (magnification, x200).

At 5-month follow-up, there is no evidence of local recurrence or distant metastasis.

\section{Discussion}

Liposarcoma, soft-tissue malignancy derived embryologically from mesodermal tissue, was first reported by Lesauvage in 1845 (9). They usually exist in the lower extremities and retroperitoneum $(10,11)$. There are four histological subtypes in liposarcoma, which include well differentiated, dedifferentiated, myxoid and pleomorphic (12). PLS are rare neoplasm which compose approximately $12 \%$ of all liposarcomas and they originate in spermatic cord mostly followed by testicular tunics and epididymis (13). When the diameter of testicular tumor reaches more than $10 \mathrm{~cm}$, such size will be called 'giant' (5). As far as we know, 200 or so cases of PLS have been reported up to date (14), and giant PLS are more rare with only a few cases having been reported (2-6). The incidence of PLS has a regional difference with the highest incidence being in Japan (7). The tumor attacked adult patients aged 50 to 60 years more frequently (15), though it occurred in patients with a range of 16 to 90 years of age on the basis of the current literature $(16,17)$. PLS mostly present as a painless, slow-growing inguinal or inguinoscrotal mass and sometimes combine with a sensation of heaviness $(9,14,16)$ and the occurrence of wrong diagnosis like scrotal lipoma, inguinal hernia and epididymitis before surgical intervention attribute to this clinical presentation $(12,15)$. Most PLS are primary, but some can be metastasis from liposarcoma at other sites, such as thigh or the fatty tissue surrounding the testicle $(18,19)$. Because of the insufficient number of literature on patients with PLS, no reliable standardized diagnosis and treatment guidelines have been made (14).

Ultrasonography (US), Computerized Tomography (CT) and Magnetic Resonance Imaging (MRI) are documented in the diagnosis of PLS $(20,21)$. On US examination, PLS are identified as solid, heterogeneous solid, hypoechoic lesions, sometimes accompanied by colliquation if there is necrosis. However, US cannot always distinguish PLS from lipomas if the tumor is small or it is a well-differentiated PLS with homogenous fatty pattern, which makes PLS similar to lipoma $(10,14,22)$. Compared to subcutaneous fatty tissue, CT usually demonstrates the tumor area with lower density. It may be helpful to establish tumor location, tissue characteristics, 
staging and follow-up $(8,16,23)$. MRI, the golden standard in staging soft tissue tumors, not only provides clear information on the tumor foci but also characterizes and delineates the degree of local tumor extension $(9,14,20)$.

Diagnosis of PLS mainly depends on histopathology, immunohistochemistry and cytomorphological features. A Critical histopathological analysis of dedifferentiated liposarcomas revealed that CD34 was negative in 9/11 cases; negative rate of s-100 was $92 \%$ (23/25); MDM2 was diffusely positive in well-differentiated areas and focally in dedifferentiated areas in the tumor with homologous dedifferentiation; SMA was positive in 2/8 tumors (24). Andrei et al proved that MDM2 and CDK4 were significative markers for confirming the diagnosis of well-differentiated liposarcoma (23). Histologically, differentiated sarcoma can be subdivided into five main subtype: Resembling pleomorphic malignant fibrous histiocytoma, fibrosarcoma, rhabdmyofibrosarcoma, myxofibrosarcoma and hemangiopericytoma $(25,26)$. A total of $76 \%$ of dedifferentiated liposarcomas was high-grade (24).

Multimodality therapy was suggested by many researchers (27-29). There is a general consensus that radical orchiectomy with wide local excision and high ligation of the spermatic cord are the current standard treatment strategies due to frequent recurrence that associated with incomplete excision (7-9,20). Because the clinical presentation of PLS is similar to scrotal lipoma or groin hernia, Immediate radical procedure should be performed to avoid the high risk of local recurrence and involvement of worsening prognosis, when a suspicious PLS is diagnosed. It is important to prohibit spillage of malignant cells and acquire a more safe edge during the operation. A clinical research showed that the 3-year local-recurrence-free survival was $100 \%$ for negative margins compared with $29 \%$ for positive margins (30). Retroperitoneal lymph node dissection is not recommended except for metastasis (7). It has been reported that occult local residual lesions were found at least a third of patients after operation (1), thus not only in dedifferentiated PLS, considered with a high rate of recurrence and metastasis, but also in other subtypes of PLS, adjuvant radiation is quite needed $(9,14,31)$. Cerda et al (32) reported that five patients with spermatic cord sarcoma given adjuvant radiotherapy with a total dose of $54 \mathrm{~Gy} / 27$ or 30 fractions were found no recurrence in median 18 months of follow-up (range 6-28 months). However, whether radiotherapy should be used as postoperative routine therapy remains to be discussed because recurrent tumor after radiotherapy may be more aggressive (10). Some suggested that radiotherapy should be used for local control $(8,10,14,30)$. There are no large studies with respect to the results of chemotherapy. A meta-analysis of 14 randomized clinical trials discovered that the improvement of recurrence and recurrence-free survival were attributed to chemotherapy $(14,33)$. Some studies reported that we should attach importance to chemotherapy for high grade LPS (1).

Research report on prognosis of PLS is quite limited until now. A recent study local-recurrence-free survival was $76 \%$ at 3 years and $67 \%$ at 5 years (30). Another study about PLS revealed the 5-year survival rate was $75 \%$ and recurrence rate was $50-70 \%$ of all cases (14). Prognosis and overall survival rate vary in accordance with some risk factors, which include tumor grade, size, depth of invasion and histopathological classification (most important). The dedifferentiated types have a worse prognosis, but local recurrence rate will be smaller $(14,34)$.

In conclusion, PLS represent a rarity of the tumor, characterized with slow growth, which are often misdiagnosed preoperatively. US, CT and MRI can redound to diagnose and differential diagnose, but the final diagnosis of PLS depends on histopathology and immunohistochemistry. When diagnosed or highly suspected preoperatively, radical orchiectomy with wide local excision and high ligation is the best treatment strategy and multimodality therapy is suggested. Long-term follow-up is recommended due to the risk of local recurrence and distant metastasis.

\section{Acknowledgements}

This study was supported by grants from the National Natural Science Foundation of China (no. 8110122), Science and Technology Development Fund Project of Shenzhen (nos.JCYJ20150403091443329 and JCYJ20170307111334308), the fund of 'San-ming' Project of Medicine in Shenzhen (no. SZSM201612066) and the fund of Guangdong Key Medical Subject.

\section{References}

1. Chiodini S, Luciani LG, Cai T, Molinari A, Morelli L, Cantaloni C, Barbareschi M and Malossini G: Unusual case of locally advanced and metastatic paratesticular liposarcoma: A case report and review of the literature. Arch Ital Urol Androl 87: 87-89, 2015.

2. Sopena-Sutil R, Silan F, Butron-Vila MT, Guerrero-Ramos F, Lagaron-Comba E and Passas-Martinez J: Multidisciplinary approach to giant paratesticular liposarcoma. Can Urol Assoc J 10: E316-E319, 2016.

3. Fernandez F and Garcia HA: Giant dedifferenciated liposarcoma of the spermatic cord. Arch Esp Urol 62: 751-755, 2009 (In Spanish).

4. Cariati A, Brignole E, Tonelli E and Filippi M: Giant paratesticular undifferentiated liposarcoma that developed in a long-standing inguinal hernia. Eur J Surg 168: 511-512, 2002.

5. Kin T, Kitsukawa S, Shishido T, Maeda Y, Izutani T, Yonese J and Fukui I: Two cases of giant testicular tumor with widespread extension to the spermatic cord: Usefulness of upfront chemotherapy. Hinyokika Kiyo 45: 191-194, 1999 (In Japanese).

6. Martin C, Olivier CM, Rengifo D, Hernandez Lao A, Ondina LM and Carballido J: Giant liposarcoma of the spermatic cord. Actas Urol Esp 17: 361-365, 1993 (In Spanish).

7. Li F, Tian R, Yin C, Dai X, Wang H, Xu N and Guo K: Liposarcoma of the spermatic cord mimicking a left inguinal hernia: A case report and literature review. World J Surg Oncol 11: 18, 2013.

8. Alyousef H, Osman EM and Gomha MA: Paratesticular liposarcoma: A case report and review of the literature. Case Rep Urol 2013: 806289, 2013.

9. Vukmirović F, Zejnilović $\mathrm{N}$ and Ivović J: Liposarcoma of the paratesticular tissue and spermatic cord: A case report. Vojnosanit Pregl 70: 693-696, 2013.

10. Raza M, Vinay HG, Ali M and Siddesh G: Bilateral paratesticular liposarcoma-a rare case report. J Surg Tech Case Rep 6: 15-17, 2014.

11. Vinayagam K, Hosamath V, Honnappa S and Rau AR: Paratesticular liposarcoma-masquerading as a testicular tumour. J Clin Diagn Res 8: 165-166, 2014.

12. García Morúa A, Lozano Salinas JF, Valdés Sepúlveda F, Zapata H and Gómez Guerra LS: Liposarcoma of the espermatic cord: Our experience and review of the literature. Actas Urol Esp 33: 811-815, 2009.

13. Noguchi H, Naomoto Y, Haisa M, Yamatsuji T, Shigemitsu K, Uetsuka H, Hamasaki S and Tanaka N: Retroperitoneal liposarcoma presenting a indirect inguinal hernia. Acta Med Okayama 55: 51-54, 2001.

14. Schoonjans C, Servaes D and Bronckaers M: Liposarcoma scroti: A rare paratesticular tumor. Acta Chir Belg 116: 122-125, 2016. 
15. Fitzgerald S and Maclennan GT: Paratesticular liposarcoma. J Urol 181: 331-332, 2009.

16. Gabriele R, Ferrara G, Tarallo MR, Giordano A, De Gori A, Izzo L and Conte M: Recurrence of paratesticular liposarcoma: A case report and review of the literature. World J Surg Oncol 12: 276, 2014.

17. Bostwick DG: Spermatic cord and testicular adnexa, 1997.

18. Fahsi O, Kallat A, Ouazize H, Dergamoun H, Sayegh HE, Iken A, Benslimane L and Nouini Y: Metastatic paratesticular liposarcoma. Pan Afr Med J 27: 101, 2017.

19. Thinyu S and Muttarak M: Role of ultrasonography in diagnosis of scrotal disorders: A review of 110 cases. Biomed Imaging Interv J 5: e2, 2009 .

20. Pergel A, Yucel AF, Aydin I, Sahin DA, GucerH and Kocakusak A: Paratesticular liposarcoma: A radiologic pathologic correlation. J Clin Imaging Sci 1: 57, 2011.

21. Yoshino T, Yoneda K and Shirane T: First report of liposarcoma of the spermatic cord after radical prostatectomy for prostate cancer. Anticancer Res 29: 677-680, 2009.

22. Montgomery E and Fisher C: Paratesticular liposarcoma: A clinicopathologic study. Am J Surg Pathol 27: 40-47, 2003.

23. Pănuş A, Meşină C, Pleşea IE, Drăgoescu PO, Turcitu N, Maria C and Tomescu PI: Paratesticular liposarcoma of the spermatic cord: A case report and review of the literature. Rom J Morphol Embryol 56: 1153-1157, 2015.

24. Rekhi B, Navale P and Jambhekar NA: Critical histopathological analysis of 25 dedifferentiated liposarcomas, including uncommon variants, reviewed at a Tertiary Cancer Referral Center. Indian J Pathol Microbiol 55: 294-302, 2012.

25. McCormick D, Mentzel T, Beham A and Fletcher CD: Dedifferentiated liposarcoma. Clinicopathologic analysis of 32 cases suggesting a better prognostic subgroup among pleomorphic sarcomas. Am J Sur Pathol 18: 1213-1223, 1994.

26. Coindre JM, Pedeutour F and Aurias A: Well-differentiated and dedifferentiated liposarcomas. Virchows Arch 456: 167-179, 2010.

27. Brennan MF, Casper ES, Harrison LB, Shiu MH, Gaynor J and Hajdu SI: The role of multimodality therapy in soft-tissue sarcoma. Ann Surg 214: 328-338, 1991.

28. Kanso C, Roussel H, Zerbib M, Flam T, Debré B and Vieillefond A: Spermatic cord sarcoma in adults: Diagnosis and management. Prog Urol 21: 53-58, 2011.
29. Sherman KL, Wayne JD, Chung J, Agulnik M, Attar S, Hayes JP, Laskin WB, Peabody TD, Bentrem DJ, Pollock RE and Bilimoria KY: Assessment of multimodality therapy use for extremity sarcoma in the United States. J Surg Oncol 109: 395-404, 2014.

30. Khandekar MJ, Raut CP, Hornick JL, Wang Q, Alexander BM and Baldini EH: Paratesticular liposarcoma: Unusual patterns of recurrence and importance of margins. Ann Surg Oncol 20: 2148-2155, 2013.

31. Song CH, Chai FY, Saukani MF, Singh H and Jiffre D: Management and prevention of recurrent paratesticular liposarcoma. Malays J Med Sci 20: 95-97, 2013.

32. Cerda T, Martin É, Truc G, Créhange G and Maingon P: Safety and efficacy of intensity-modulated radiotherapy in the management of spermatic cord sarcoma. Cancer Radiother 21: 16-20, 2017.

33. Gago Juan A, Luján Galán M, Bustamante Alarma S, Fernández Lobato R, Zárate Rodríguez E, Martín Osés E and Berenguer Sánchez A: A paratesticular myxoid liposarcoma as a simulator of a hernial process. A case report. Arch Esp Urol 50: 921-923, 1997.

34. Stranne J, Hugosson J and Lodding P: Post-radical retropubic prostatectomy inguinal hernia: An analysis of risk factors with special reference to preoperative inguinal hernia morbidity and pelvic lymph node dissection. J Urol 176: 2072-2076, 2006. 